\title{
Empirical Comparisons of Survey Designs in Acoustic Surveys of Gulf of Maine-Georges Bank Atlantic Herring
}

\author{
W. J. Overholtz, J. M. Jech, W. L. Michaels, and L. D. Jacobson \\ NOAA/NMFS Northeast Fisheries Science Center \\ Woods Hole, MA 02543, USA \\ P. J. Sullivan \\ Department of Natural Resources \\ Cornell University, Ithaca, NY, USA
}

\begin{abstract}
Overholtz, W. J., J. M. Jech, W. L. Michaels, and L. D. Jacobson. 2006. Empirical comparisons of survey designs in acoustic surveys of Gulf of Maine-Georges Bank Atlantic herring. J. Northw. Atl. Fish. Sci., 36: 127-144. doi: 10.2960/J.v36.m575
\end{abstract}

\begin{abstract}
Three different hydroacoustic survey designs (parallel, zigzag, and stratified random) were used to survey Atlantic herring (Clupea harengus) on Georges Bank during 2000 and 2001. The surveys covered the pre-spawning distribution of herring from the northern edge of Georges Bank to Nantucket Shoals, spanning a linear distance of roughly $300 \mathrm{~km}$. The goal was to establish a practical survey design and methods for analysis of population estimates of herring in the northwest Atlantic Ocean. Analyses of acoustic transect data using a classical (design based) approach and a model based (geostatistical) approach were completed, so that the properties of the three survey designs could be compared. Herring were distributed across the entirety of the western side of Georges Bank between the $50-150 \mathrm{~m}$ isobaths in all surveys during both years. Mean herring backscatter $\left(s_{A}\right)$ was similar for the three surveys during 2000 and 2001; the mean from the parallel design was the highest in both years, due to a few very large observations and also the timing of the surveys. Coefficients of variation for the three surveys ranged from 23\% for the zigzag design in 2001 to $44 \%$ for the stratified random design in 2000 using design based estimators and between $10 \%$ for the parallel design in 2001 to $17 \%$ for the stratified random design in 2000 using model-based methods. Herring biomass (geostatistical estimates) analyzed using meta-analysis, ranged between 1.27 and 1.58 million mt during 2000 and between 1.60 and 2.14 million metric tons during 2001. Bootstrap results suggest that herring biomass is generally well estimated by all three designs. The zigzag design provided the lowest average $\mathrm{CV}$ over the two years, while the parallel design in 2001 produced the lowest $\mathrm{CV}$ for the six surveys. Overall, the systematic designs were robust in capturing the relatively strong spatial signal in the herring distribution data, while the stratified random design performed relatively poorly in this regard in both years.
\end{abstract}

Key words: Atlantic herring, geostatistics, hydroacoustic survey, survey design

\section{Introduction}

Atlantic herring (Clupea harengus), hereafter referred to as 'herring', in the Gulf of Maine-Georges Bank region (Fig. 1) have been the focus of intense fisheries for several centuries and were heavily exploited during the 1960s and 1970s by distant water fleets from Europe and the former Soviet Union (Anthony and Waring, 1980; Tupper et al., MS 1998). Total landings increased dramatically to about 470000 metric tons (mt) in 1968 and then declined precipitously with an attendant collapse of the Georges Bank component in 1977 (Anthony and Waring 1980). Stock recovery was delayed by roughly 20 years because of little or no recruitment and high predation mortality rates (Overholtz et al., MS 2004; Overholtz et al., in prep.). The stock complex has only recently recovered after a decade of improved recruitment and relatively low fishing mortality (Smith and Morse, 1993; Overholtz and Friedland, 2002; Overholtz et al., MS 2004).

Herring from the Gulf of Maine-Georges Bank complex have been the subject of stock assessment work since the early 1960s and analytical procedures have been applied since the early 1970s (Anthony and Waring, 1980; Tupper et al., MS 1998). Initial research recognized that 3 main groups of herring were associated with distinct 


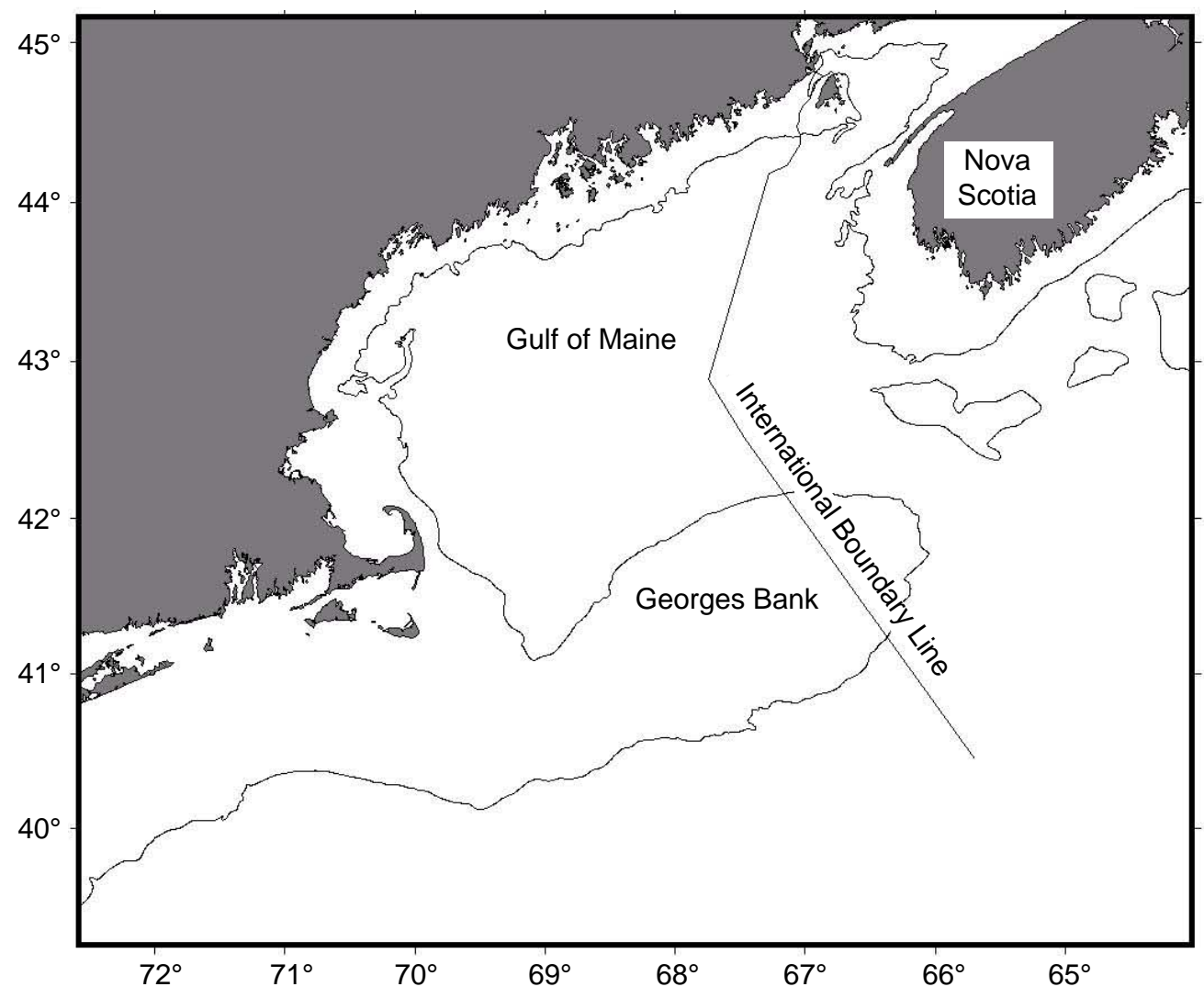

Fig. 1. Location map for Georges Bank, Gulf of Maine, and the Hague Line demarcation between the USA and Canada.

spawning locations; coastal Maine and Massachusetts, Nantucket Shoals, and Georges Bank (Anthony and Waring, 1980; Tupper et al., MS 1998). Early attempts at modeling stock dynamics relied on untuned VPAs or cohort analyses without the benefit of fishery independent information for stock trends or recruitment. The various components were assessed separately prior to 1991, and thereafter the entire complex has been assessed as a single stock (Anthony and Waring, 1980; Fogarty and Clark, MS 1983; Overholtz et al., MS 2004).

Bottom trawl surveys conducted by both the United States and Canada have been used to model population trends for the herring complex and to track abundance, but have been difficult to interpret quantitatively. Although the survey time-series are valuable and have been used in tuning previous assessments, there are some limitations. For example, the US winter, spring, and autumn research bottom trawl series all occur during seasons and in areas where the stock complex is mixed, so disaggregating indices into the various components is difficult. These indices can also be highly variable, exhibiting significant annual variability due to environmental forcing, changes in herring behavior, or changes in survey gear or timing.
As such interpretation of bottom trawl survey trends is difficult.

For these reasons, in 1998 an acoustics research and monitoring survey was initiated for pre-spawning herring on the offshore (Georges Bank) component of the herring complex. A complementary acoustics survey, utilizing commercial vessels, began in 1999 and covered the inshore component along the coasts of Massachusetts and Maine (Michaels and Yund, MS 2001). The objective of these surveys is to determine the spatial distribution, abundance, and biomass of the major spawning components within the herring complex. Because acoustical surveys were not conducted prior to 1998, fundamental information and data on behavior, abundance, and the spatial-temporal distribution of herring in this region were lacking. To obtain this information, a multi-faceted approach was employed, which included in situ target strength measurements, underwater video, biological sampling, and designing an optimal survey (Jech et al., 2000; Overholtz et al., MS 2004).

This paper compares biomass estimates from three different survey designs: systematic parallel, systematic 
zigzag, and stratified random, and two different analyses: geostatistical methods and conventional statistics with bootstrapping. The goal is to establish a practical survey design and methods for analysis of population estimates of herring in the northwest Atlantic Ocean. Analyses of acoustic transect data using a classical (design based) approach and a model based (geostatistical) approach were completed so that the properties of the three survey designs could be compared.

\section{Materials and Methods}

\section{Acoustic Data}

Acoustic data were collected with a Simrad EK 500 scientific echo sounder operating at 12, 38, and $120 \mathrm{kHz}$. The downward-looking, hull mounted singlebeam $(12 \mathrm{kHz})$ and split-beam $(38$ and $120 \mathrm{kHz})$ transducers were calibrated prior to and during the surveys using the standard target method described by Foote et al. (1987). Analyses presented here used only the $38 \mathrm{kHz}$ data, as $38 \mathrm{kHz}$ is the de facto standard acoustic frequency for abundance estimates of marine fishes. Operational parameters for the $38 \mathrm{kHz}$ echo sounder were a $1 \mathrm{~ms}$ pulse duration and 1 transmission per 2 seconds. The Simrad split-beam ES38-12 transducer had a $12^{\circ}$ beam width (as defined by the total angular distance between half-power points). Echo integration data were processed into $1 \mathrm{~m}$ vertical bins by the EK500 and transmitted via Ethernet to a UNIX workstation. Post-processing was done in SonarData's Echoview v.2.25 software package (SonarData Pty Ltd., GPO Box 1387 Hobart, Tasmania, Australia. www. sonardata.com). (Post-processing included elimination of data deeper than $0.5 \mathrm{~m}$ above the seabed echo and shallower than $10 \mathrm{~m}$ below the surface, removal of acoustical and electrical noise, and visual identification of herring aggregations. Volume backscatter $\left(S_{v}\right)$ data were integrated and averaged throughout the water column and over 0.5 nautical miles (nmi) (Elementary Distance Sampling Unit (EDSU)) to give Nautical Area Scattering Coefficients (NASC, symbol $\left.s_{A}\right)$ values $\left(\mathrm{m}^{2} \mathrm{nmi}^{-2}\right.$, MacLennan et al., 2002). NASC values for the entire water column and NASC values attributed to herring were exported to an Oracle database. NASC values used in this study are only those attributed to herring.

Apportioning acoustic backscatter to herring was accomplished using trawl catch information from a HighSpeed Midwater Rope Trawl (HSMRT) and underwater video footage targeted at backscattering layers and aggregations. This trawl was towed at 4-5 knots, and had a mouth opening of 300-350 $\mathrm{m}^{2}$ when being towed at these speeds. Trawl hauls and underwater video collection were selected on an ad hoc basis. Tow depths were determined immediately prior to each trawl and were selected to sample backscatter thought to be herring. Supplementary tows were also conducted to sample backscatter not believed to be herring, so as to improve interpretation of the acoustic echograms. Tow duration was based on real-time mensuration with the Simrad FS900 and was not standardized. Due to logistic constraints of completing the three survey designs, trawl locations were distributed among the three surveys so as to cover the survey area. Ultimately, acoustic backscatter was visually apportioned to herring based on previous experience with trawl catches, underwater video images, and visual analysis of the 12,38, and $120 \mathrm{kHz}$ echograms.

\section{Survey Design}

Pilot acoustical surveys during 1998-99 suggested that pre-spawning herring aggregations extended from the Great South Channel to slightly beyond the Hague Line on the northern edge of Georges Bank. Three designs, systematic parallel, systematic zigzag, and a stratified random were employed in 2000 to survey herring (Table 1; Figs. 2a-c). These surveys were designed to cover the entire extent of the spawning aggregations and to provide additional spatial, temporal, and quantitative information for conducting future surveys. The systematic zigzag and parallel surveys used $10 \mathrm{nmi}$ spacing between transect nodes. The $10 \mathrm{nmi}$ spacing was chosen to optimize coverage of the herring distribution with logistics of completing the surveys in the allotted time. The north-south orientation of the transects was chosen to be approximately perpendicular to the major bathymetric features.

Three survey strata were identified in the stratified random survey, corresponding to three strata.. These strata were selected on the basis of bathymetry, geographic features (i.e., the Great South Channel, Cultivator Shoals, and the northern edge of Georges Bank), and knowledge of the spatial distribution of herring obtained from previous surveys. Transects were allocated to strata based on the stratum area, and the amount of herring habitat in each stratum. In 2000, sets of 13 possible transects in strata 1 and 2 and 12 transects in stratum 3 were defined with $5 \mathrm{nmi}$ spacing between transects. Of these sets of potential transects, five transects were randomly selected in each of strata 1 and 2, and four were randomly selected in Stratum 3.

Coverage of the Georges Bank region in 2001 was similar to coverage in 2000, but some transects were extended to ensure more complete coverage of the spawning concentrations (Table 1). In addition, several transects were added to the stratified random survey in 2001 to increase the sample size in each stratum. This was done to improve the precision of the stratified random data and the symmetry of the bootstrap distribution. Spacing of the 
TABLE 1. Beginning and end dates and type of survey patterns for the surveys conducted in 2000 and 2001.

\begin{tabular}{|c|c|c|c|c|}
\hline Survey & Begin Date & End Date & $\begin{array}{c}\text { No. } \\
\text { of } \\
\text { Transects }\end{array}$ & $\begin{array}{c}\text { Total } \\
\text { Transect } \\
\text { Length nmi }\end{array}$ \\
\hline \multicolumn{5}{|c|}{2000} \\
\hline Systematic Parallel & 11 Sept. & 16 Sept. & 15 & 269.0 \\
\hline Stratified Random & 19 Sept. & 24 Sept. & 14 & 369.0 \\
\hline Systematic Zigzag & 24 Sept. & 29 Sept. & 20 & 527.5 \\
\hline \multicolumn{5}{|c|}{2001} \\
\hline Systematic Parallel & 18 Sept. & 22 Sept. & 14 & 375.5 \\
\hline Stratified Random & 22 Sept. & 27 Sept. & 19 & 439.5 \\
\hline Systematic Zigzag & 3 Oct. & 7 Oct. & 19 & 553.0 \\
\hline
\end{tabular}

transects for the stratified random survey was modified from 5 to $3 \mathrm{nmi}$ and the number of possible transects in both strata 1 and 2 was increased to 21, and to 19 in Stratum 3. Of these, seven transects were sampled in Strata 1 and 2, and six in Stratum 3.

\section{Biological Data}

Mid-water trawl hauls were conducted during all surveys to confirm the species composition of the acoustic backscatter. Mid-water trawl samples were separated by species, weighed $(\mathrm{g})$, measured (total length $\left(L_{T L}\right)$ and/or fork length $\left.\left(L_{F L}\right), \mathrm{cm}\right)$, and all information recorded on trawl logs or in the Fisheries Scientific Computer System (Benigni et al., 2004) electronic database management system. In addition, herring were sub-sampled for age determination, diet composition, and maturity stage.

Length-weight equations were developed from herring samples collected during National Marine Fisheries Service (NMFS) autumn bottom trawl surveys. Lengthweight data from the autumn bottom trawl surveys were used because herring collected during the acoustical surveys were experiencing rapid changes in weight due to spawning, and were not useful for estimating a general equation. Non-linear regression was used to estimate the parameters of the length-weight equation $W=a L_{F L}{ }^{b}$, where $W$ is the weight in $\mathrm{kg}, L_{F L}$ is fork length in cm and $a$ and $b$ are empirically-derived regression parameters.

Data collected in 1999 were used in developing a fork length-total length regression equation for herring. Fork length $\left(L_{F L}\right)$ measurements were converted to total length $\left(L_{T L}\right)$ using:

$$
L_{T L}=0.01+1.103 L_{F L}
$$

Herring length data from each survey during 2000-01 were converted to total length for use in the target strength analyses. Length samples were aggregated for each survey by weighting each available transect length sample with the echo intensity $\left(s_{A}\right)$ for that transect, summing, and calculating a weighted average for each length. This weighted length composition for each survey was then used to calculate an average weight for each length in the survey.

\section{Data Analysis}

Two analytical methods were applied to the transect data, geostatistical analysis (model based) and conventional statistical analysis (design based) with bootstrapping, to evaluate the utility and potential advantages of either method for estimating population abundance and biomass of herring.

\section{Model-Based Analysis}

Atlantic herring NASC values for each survey were plotted using GIS software and polygons visually drawn to encompass the herring distribution. Polygons included zero values when these NASCs were surrounded by herring NASC, but excluded sections at the end of a transect with no occurrence of a herring NASC. Areas of each survey region were tabulated and then analyzed with the SPLUS geostatistical software package (ver. March 2000) (Kaluzny et al., 1997). Geographical locations of the herring NASC data were transformed from longitude and latitude (in decimal degrees) to a grid in nautical mile format where the original spacing between locations was not altered. The average latitude within survey areas was used to transform geographic locations using a simple cosine function.

Spherical models have been routinely fitted to data to determine estimates of abundance for herring in the North Atlantic (Petitigas, 1993; Maravellias et al. , 1996; Rivoirard et al., 2000). For this reason and because this 
OVERHOLTZ et al.: Acoustic Surveys of Atlantic Herring
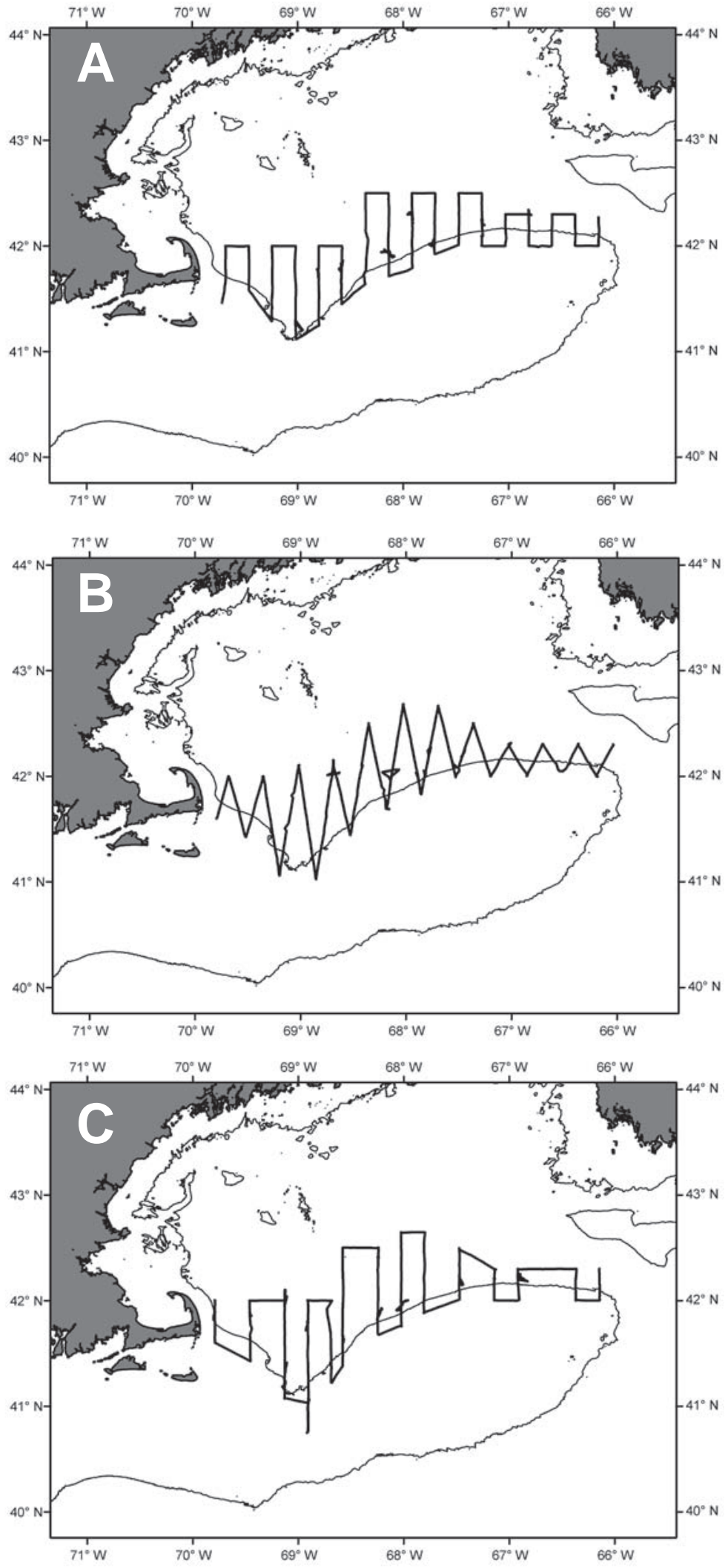

Fig. 2. Example cruise designs for herring research acoustic survey on Georges Bank in 2000: (A) parallel, (B) zigzag, and (C) stratified random. 
model fit (visual inspection) the Georges Bank herring survey data fairly well, spherical models were used in all subsequent analyses. The parameters for each survey were fit by using the software to perform repeated trials until the mean square error was minimized. Because there were some extreme values and skewness in each set of survey data, robust variograms were fit to all the surveys to reduce this source of variability (Cressie and Hawkins, 1980). This allowed for the impact of particularly noisy data to be reduced, while still being included in the analysis. In order to use a model based approach the data must be linearly related or isotropic to distance (Goovaerts, 1997). The data for each survey were analyzed to determine if a correction for geometric anisotropy was needed. Directional variograms were examined using procedures outlined in Kaluzny et al. (1997) to determine if there was an angular $(0,45,90,135$ degrees $)$ trend in the data using graphical output. If a trend was evident the data were corrected by rotating and changing the ratio of the data ellipse so that any trend was eliminated. This was done by examining graphical outputs and deciding on an appropriate angle of rotation and data ratio to correct the problem. The maximum analysis distance for each survey was set at $50 \mathrm{nmi}$ to remove the impact of additional distant spatial noise on variogram fitting. This distance was determined by visually inspecting variograms at successively smaller maximum distance cutoffs. At $50 \mathrm{nmi}$ the variogram fit improved greatly, removing much of the additional variability in the data. Spherical variograms were used to Krige the NASC data. The kriging routine available in the software package was used to provide an estimate of the mean and standard deviation of the herring NASC from the six surveys (Kaluzny et al., 1997).

\section{Design-Based Analysis}

The mean herring NASC for systematic parallel and zigzag surveys was calculated using methods described by Jolly and Hampton (1990). First, the mean NASC for each transect $\left(s_{A}(j)\right)$ was calculated by averaging NASC values along individual transects. The mean transect NASCs were then weighted by the corresponding transect lengths:

$$
\overline{S_{A}}(i)=\frac{1}{N_{T}(i)} \sum_{j=1}^{N_{T}(i)} w_{T}(j) \overline{S_{A}}(j)
$$

where $i$ is the survey index, $j$ is the transect index, $N_{T}(i)$ is the number of transects in the $i^{\text {th }}$ survey, and $w_{T}$ is the transect-length weighting coefficient,

$$
w_{T}(j)=\frac{L_{T}(j)}{\bar{L}_{T}(i)}
$$

where $L_{T}(j)$ is the individual transect length, and $\bar{L}_{T}$ is the mean transect length for the survey.
The mean herring NASC for stratified random surveys was calculated similar to the systematic parallel and zigzag surveys, except that each stratum was weighted individually, and then strata were combined by weighting stratum mean NASC by each stratum area:

$$
\overline{S_{A}}(i)=\frac{\sum_{n=1}^{N_{s}} A(n) \overline{S_{A}}(n)}{\sum_{n=1}^{N_{s}} A(n)}
$$

where $A(n)$ is the area $\left(\mathrm{nmi}^{2}\right)$ and $s_{A}(n)$ is the weighted mean herring NASC of the $n^{\text {th }}$ stratum, and $N_{S}$ is the number of strata.

\section{Target Strength Analysis}

No local target strength (TS) to length regression is currently available for converting echo intensity to abundance and biomass for herring in the northwest Atlantic. Therefore, a meta-analysis was performed to generate a TS-length regression for scaling relative indices. This method does not replace establishing a herring target strength-length regression for Georges Bank, but it allows for the utilization of available information. A meta-analysis approach was used so that the combined results from several studies could be utilized to draw conclusions about the abundance and biomass of herring in the region. This meta-analysis used the intercepts from eleven TS-length equations for other herring stocks in the North Atlantic (ICES, MS 2001) (Table 2) to estimate herring target strength.

For this meta-analysis, these intercepts were used in the standard form of the TS-length equation, $T S_{m}=20 \log _{10}\left(L_{T L}\right)+I_{m}(\mathrm{~dB})($ Foote 1991), where length

TABLE 2. Intercepts of target strength-length equations and acoustic frequency from studies on herring stocks in the North Atlantic during 1982-99.

\begin{tabular}{lc}
\hline \hline Study & Intercept \\
\hline Hagstrom and Rottigen, MS 1982 & -73.5 \\
Halldorsson and Reynisson, MS 1983 & -69.4 \\
Degnbol et al., 1985 & -72.6 \\
Lassen and Staehr, MS 1985 & -70.8 \\
Foote et al., 1986 & -72.1 \\
Foote, 1987 & -71.9 \\
Rudstam et al., 1988 & -69.9 \\
Bailey and Simmonds, 1990 & -71.2 \\
Reynisson, MS 1993 & -67.1 \\
Misund and Beltstad, 1995 & -69.8 \\
Vabo et al., 1999 & -67.6 \\
\hline
\end{tabular}


$L_{T M}$ is total length (cm), $I$ is the intercept $(\mathrm{dB})$, and $m$ indexes intercepts from each study. For each length interval $l$ and intercept, target strength was converted to backscattering cross-section $\left(\sigma_{b s}, m^{2}\right)$,

$$
\sigma_{b s_{m}}\left(L_{l}\right)=10^{\left(T S_{m}\left(L_{l}\right) / 10\right)} \quad\left[m^{2}\right]
$$

A mean backscattering cross-section $\left(\bar{\sigma}_{b s}\right)$ was calculated for each survey and each intercept by weighting $\sigma_{b s}$ by the weighted length-frequency distribution:

$$
\bar{\sigma}_{b s_{m}}(i)=\sum_{l=1}^{N_{L}} \varpi_{l} \times \sigma_{b s_{m}}\left(L_{l}\right) \quad\left[m^{2}\right]
$$

where $\varpi_{l}$ are the proportional weights, $N_{L}$ is the number of length intervals, and the summation of $\varpi_{l}=1$. For each intercept and survey, the abundance $\left(N_{m}(i)\right)$ and biomass $\left(B_{m}(i), \mathrm{kg}\right)$ were calculated:

$$
\begin{aligned}
& N_{m}(i)=\frac{\overline{S_{A}}(i)}{4 \pi \bar{\sigma}_{b s_{m}}(i)} \times A(i) \\
& B_{m}(i)=N_{m}(i) \times \bar{W}(i)
\end{aligned}
$$

where $\overline{S_{A}}$ is the mean NASC derived from geostatistical analysis, $A$ is the total surveyed area $\left(\mathrm{nmi}^{2}\right)$, and $\bar{W}$ is the mean weight, weighted by the length-frequency distribution:

$$
\bar{W}(i)=\sum_{l=1}^{N_{L}} \varpi_{l} \times W_{l} \quad[\mathrm{~kg}]
$$

A mean biomass for each survey was calculated by averaging over the biomass estimates for the eleven intercepts. Biomass estimates (model based) from the surveys were weighted by the inverse of the geostatistical coefficient of variation (CV or $\sigma / \mu$, Snedecor and Cochran, 1972) for each survey, and a weighted mean biomass calculated for each survey year.

\section{Bootstrapping}

A bootstrap analysis was used to evaluate the precision of the survey biomass estimates from the design based data. Survey data from the two systematic designs (parallel and zigzag), according to classical statistical theory, cannot be used to produce an estimate of variance. Therefore, bootstrap results from all the surveys were scaled by the geostatistical variance using an approach outlined in Simmonds (2002):

$$
\bar{S}_{A}(i)=u_{\text {boot }}-\left(u_{\text {geo }}-u_{\text {boot }}\right) \sqrt{\frac{\sigma^{2} \text { geo }}{\sigma^{2} \text { boot }}}
$$

Where $\mu_{\text {boot }}$ and $\mu_{\text {geo }}$ are the bootstrap and geostatistical mean values, and $\sigma_{\text {boot }}^{2}$ and $\sigma_{\text {geo }}^{2}$ are the bootstrap and geostatistical variance. The transect mean NASCs from each survey were bootstrapped 2500 times and scaled with the geostatistical variance using the above equation (Simmonds, 2002).

\section{Results}

During the 2000 systematic parallel survey, herring were distributed from Nantucket Shoals to the northern edge of Georges Bank (Fig. 3a). Herring were abundant between the 100 and $200 \mathrm{~m}$ isobaths and broadly distributed in the western and central parts of the survey area. Herring were most abundant in the central part of the area, with few fish found at the western and eastern extremes of the area. In the 2000 systematic zigzag survey, herring were distributed along the northern portion of Georges Bank (Fig. 3b). Herring were abundant between the 100 and $200 \mathrm{~m}$ contours, with fish particularly abundant in the middle section of the survey area, adjacent to the Cultivator Shoals region with fewer herring occurring at the western and eastern most sampling locations. The stratified random survey corroborated the broad east-west distribution of herring. Herring were abundant between the 100 and $200+m$ isobaths and were widely distributed in the western and central areas (Fig. 3c). Abundance was greatest in the central area with few herring observed in the outermost western and eastern transects.

In the 2001 systematic parallel survey, herring were abundant between the 50 and $200 \mathrm{~m}$ contours and were concentrated in the central and western areas adjacent to Georges Bank (Fig. 4a). Herring were also abundant within the 50 to $100 \mathrm{~m}$ contours from the Great South Channel to the Northern Edge in both the systematic zigzag and stratified random surveys (Fig. 4b, c). As in 2000, the highest NASC values were observed in the central region, in deeper water to the west, and along the $100 \mathrm{~m}$ depth contour to the east.

Design-based estimates of the mean herring NASC and variance in herring NASC were calculated for each of the three surveys in both years. Estimates of the standard deviation and coefficient of variation (CV) for the systematic zigzag and parallel surveys are provided for comparison purposes only. Mean NASCs ranged from $1053-2132 \mathrm{~m}^{2} \mathrm{nmi}^{-2}$ in 2000 and $1168-1998 \mathrm{~m}^{2} \mathrm{nmi}^{-2}$ in 2001 (Table 3 ). The CV for the systematic zigzag survey was the smallest of the three designs in each year. The mean of the systematic parallel designs was larger in both years due primarily to the presence of a single, very large NASC value in each of these surveys. Coefficients of variation ranged from 32\%-44\% in 2000 and 23\%-39\% in 2001 (Table 3). 

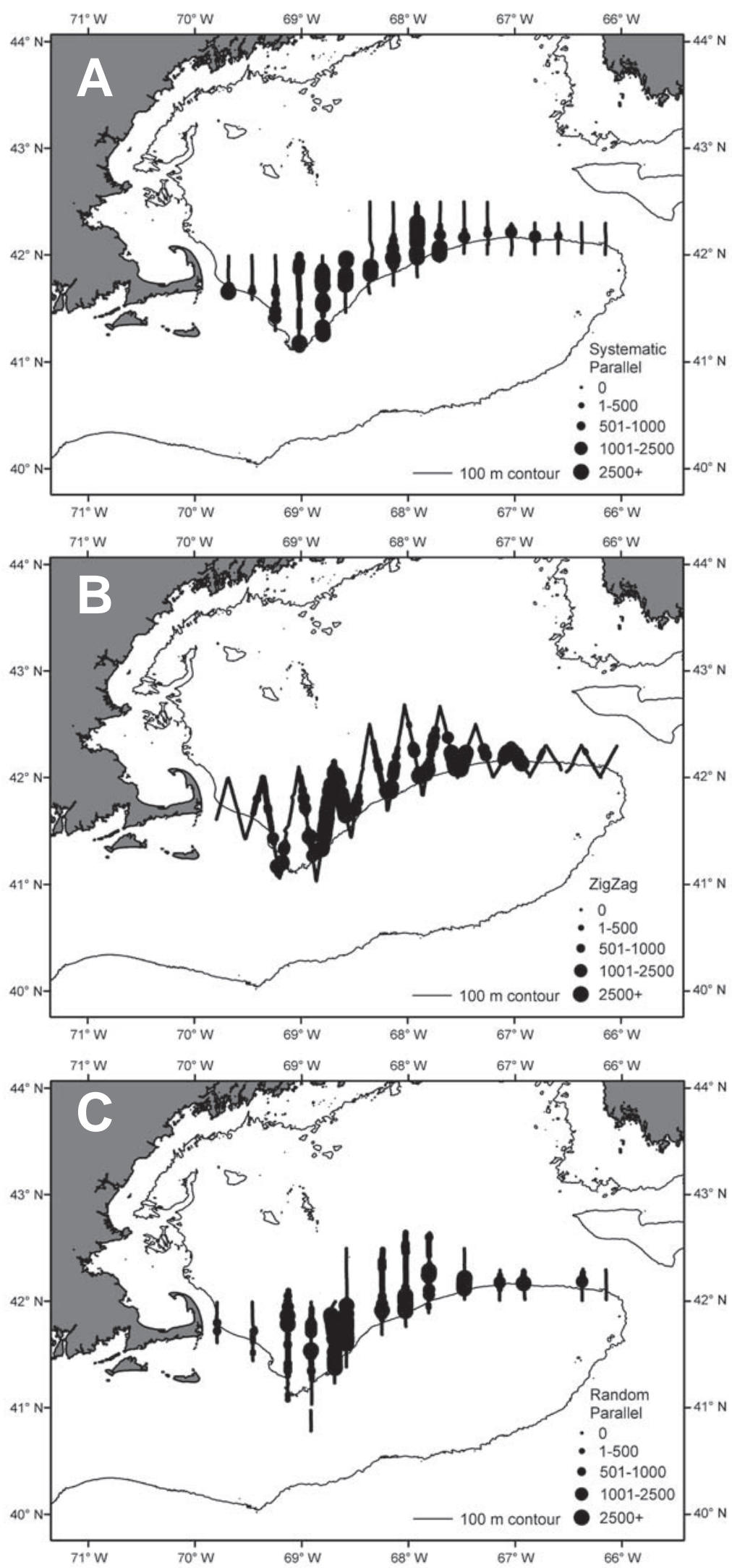

Fig. 3. Herring NASC along transects on Georges Bank in 2000: (A) parallel, (B) zigzag, and (C) stratified random survey. 

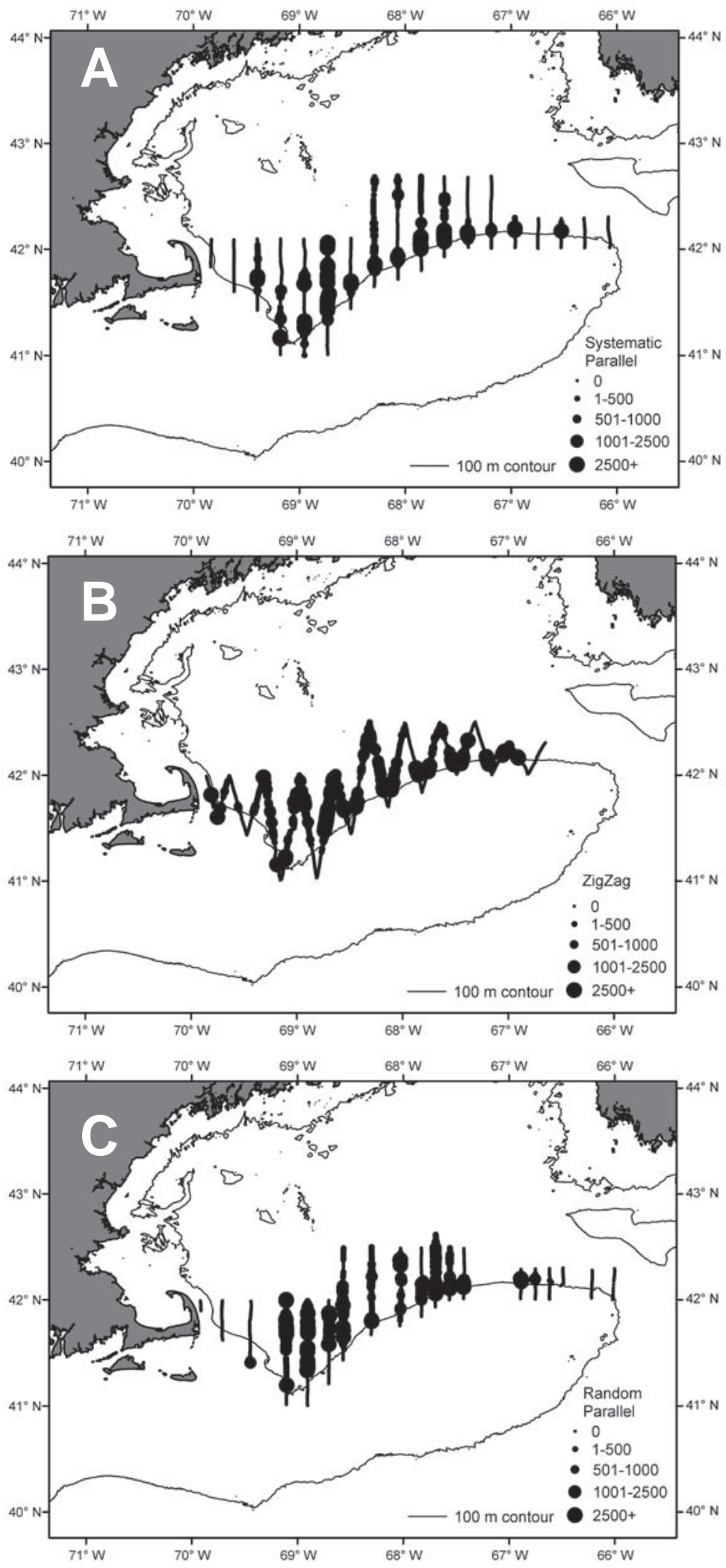

Fig. 4. Herring NASC along transects on Georges Bank in 2001: (A) parallel, (B) zigzag, and (C) stratified random survey. 
TABLE 3. Mean herring NASC $\left(\mathrm{m}^{2} \mathrm{nmi}^{-2}\right)$, standard deviation (SD) $\left(\mathrm{m}^{2} \mathrm{nmi}^{-2}\right)$, and coefficient of variation (CV) for design-based and model-based estimates.

\begin{tabular}{|c|c|c|c|c|c|c|}
\hline \multirow[b]{2}{*}{ Survey } & \multicolumn{2}{|c|}{ Mean } & \multicolumn{2}{|c|}{ SD } & \multicolumn{2}{|c|}{$\mathrm{CV}$} \\
\hline & Design & Model & Design & Model & Design & Model \\
\hline & \multicolumn{6}{|c|}{2000} \\
\hline Systematic Parallel & 2132 & 1824 & 739 & 210 & 35 & 11 \\
\hline Stratified Random & 1291 & 1191 & 567 & 201 & 44 & 17 \\
\hline \multirow[t]{2}{*}{ Systematic Zigzag } & 1053 & 1065 & 342 & 106 & 32 & 10 \\
\hline & \multicolumn{6}{|c|}{2001} \\
\hline Systematic Parallel & 1998 & 1823 & 773 & 180 & 39 & 10 \\
\hline Stratified Random & 1168 & 1256 & 358 & 192 & 31 & 15 \\
\hline Systematic Zigzag & 1448 & 1453 & 327 & 157 & 23 & 11 \\
\hline
\end{tabular}

Spherical models and the transformations that were applied seemed to provide a useful fit to the data for the three survey designs, generally suggesting that there is a strong spatial signal in the herring acoustic survey information. Both classic and robust variograms were examined, but the robust variograms seemed more stable, had fewer extreme values, and seemed to delineate the range better than the classic approach (Figs. 5 and 6). We judged the robust approach to be more useful for our application. The range (signal distance in nmi), sill (variogram height), and nugget (intercept) parameters for these models were similar among survey designs during the two years, with the exception of the zigzag surveys (Table 4). The two stratified random surveys had parameters that were relatively different than the two systematic surveys. The range for both stratified random surveys was 10-12, while it was 16-25 for the systematic surveys (Table 4).

Model-based estimates of herring backscatter (NASC) ranged between 1065-1824 in 2000 and between 1256-1823 in 2001 (Table 3). The CVs of these estimates were smaller than design-based CVs, ranging between $10 \%-17 \%$ in 2000 and $10 \%-15 \%$ in 2001 . The systematic zigzag survey produced the lowest average CV for the two years, while the systematic parallel design in 2001 produced the lowest CV for the 2000-01 surveys (10\%) (Table 3). The CVs for the stratified-random surveys were highest during both years, most likely due to randomly designed approaches not accounting as well for spatial autocorrelation (Rivoirard et al., 2000).

Meta-analysis of target strength intercept data proved useful for estimating herring biomass from the 2000-01 surveys. The suggested distribution of intercept values from the eleven Target Strength studies occurred at a median value of $-70.8 \mathrm{~dB}$. Because the slope was fixed at 20 , the target strength-length regression is dependent on the intercept. The intercepts ranged from -67.1 to -73.5 $\mathrm{dB}$ and this $6.4 \mathrm{~dB}$ range equates to a factor of four in backscattering cross-section, which translates into a factor of four in abundance estimates.

Biomass estimates based on model-based NASCs ranged from 1.3 to 1.6 million $\mathrm{mt}$ in 2000 and 1.6 to 2.1 million $\mathrm{mt}$ in 2001 (Table 5). The average biomass in 2000 was 1.4 million $\mathrm{mt}$ and 1.8 million $\mathrm{mt}$ in 2001 . Bootstrap distributions of biomass (design based) were similar among all the surveys with the exception of the stratified random survey in 2000 (Figs. 7 and 8). The biomass distribution for the stratified random survey in 2000 was highly skewed relative to the other distributions. This skewness resulted from too few transects being allocated to each stratum. When more transects were allocated to each stratum in 2001, the biomass distribution was similar to the other surveys (Fig. 8). The median biomass for the 2000 surveys ranged between 1.3 and 1.8 million $\mathrm{mt}$ with an $80 \% \mathrm{CI}$ between 1.1 and 2.2 million $\mathrm{mt}$ and between 1.5 and 2.3 million $\mathrm{mt}$ with $80 \% \mathrm{CI}$ between 1.2 and 2.6 million $\mathrm{mt}$ in 2001 (Table 6, Fig. 9). Biomass estimates tended to be higher in 2001 than in 2000, which may be due to the growth of several large year classes of herring (Overholtz et al., MS 2004).

\section{Discussion}

Generating a population estimate is a marriage of survey design and data analysis. Survey design is an exercise in optimization, where logistic constraints often dictate the level of effort that can be expended to survey a population. One hundred percent coverage is a lofty goal, 
OVERHOLTZ et al.: Acoustic Surveys of Atlantic Herring
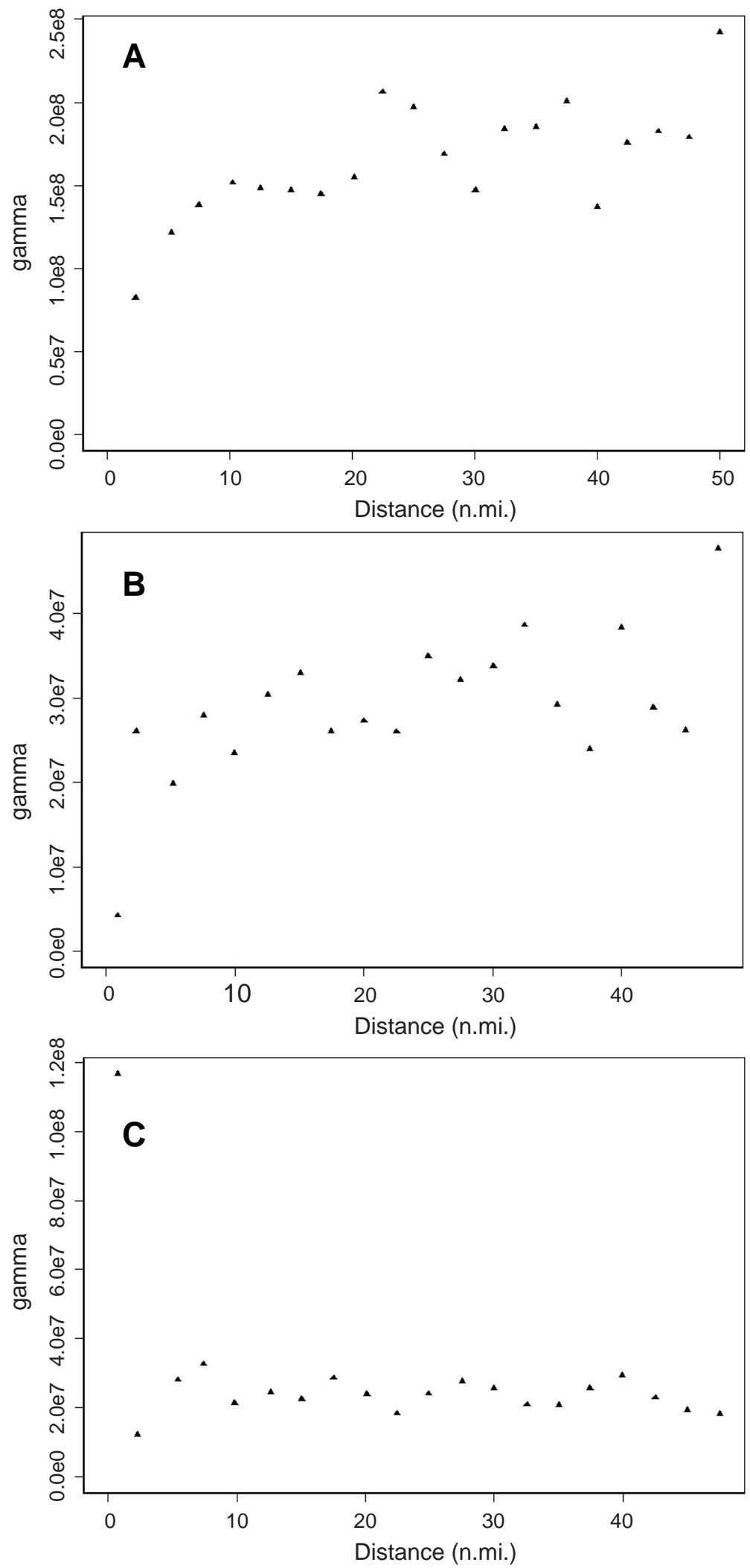

Fig. 5. Classic variograms for 2001 surveys on Georges Bank: (A) parallel, (B) zigzag, and (C) stratified random. 

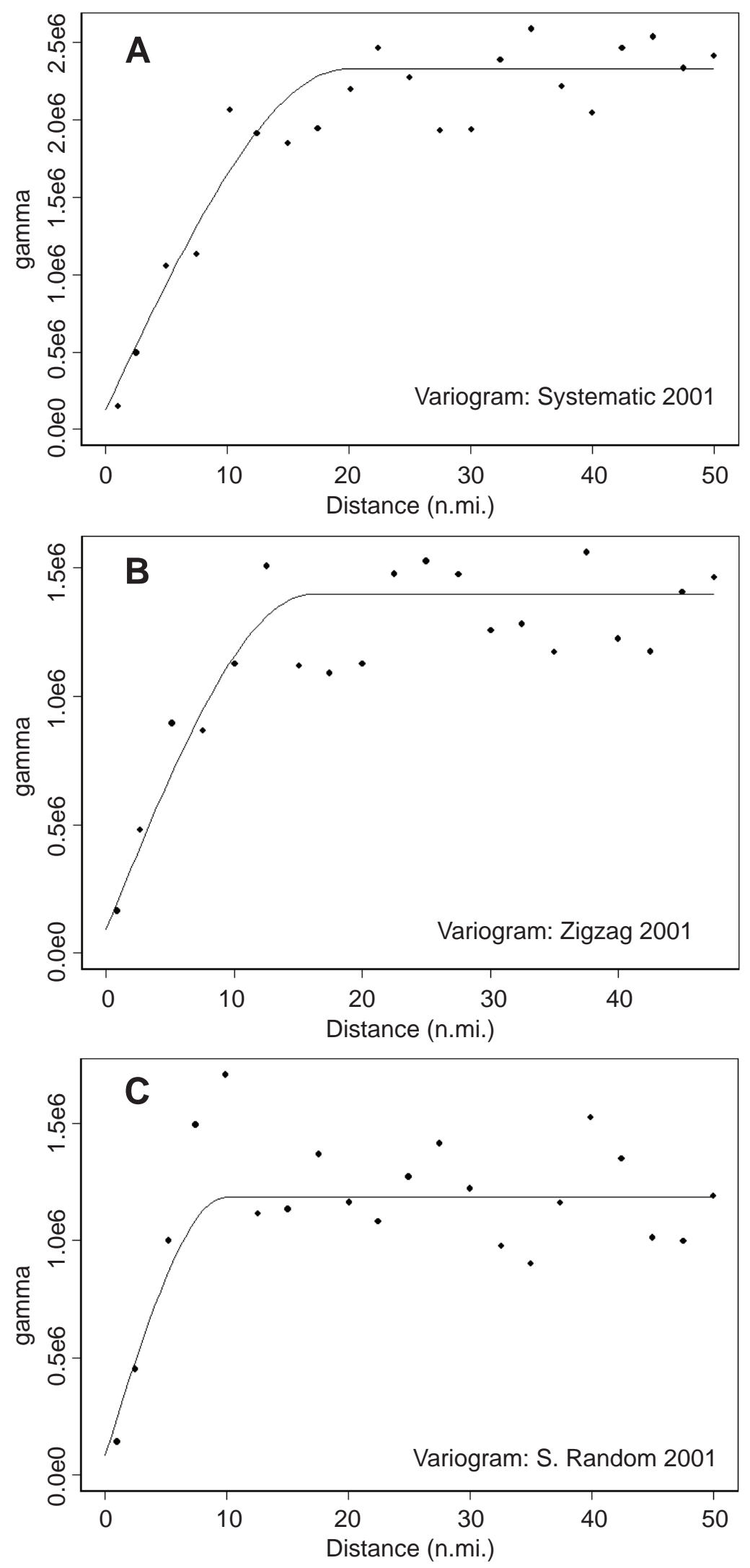

Fig. 6. Example variograms from surveys on Georges Bank in 2001: (A) parallel, (B) zigzag and (C) stratified random. 
TABLE 4. Parameters from spherical variogram fits for hydroacoustic surveys on Georges Bank during 2000 to 2001.

\begin{tabular}{|c|c|c|c|}
\hline Survey & Range & Sill & Nugget \\
\hline \multicolumn{4}{|c|}{2000} \\
\hline Systematic Parallel & 18.0 & $2.7 \mathrm{e} 6$ & $1.9 \mathrm{e} 5$ \\
\hline Stratified Random & 11.8 & $1.2 \mathrm{e} 6$ & $8.5 \mathrm{e} 4$ \\
\hline Systematic Zigzag & 25.0 & $9.5 \mathrm{e} 5$ & $6.1 \mathrm{e} 4$ \\
\hline \multicolumn{4}{|c|}{2001} \\
\hline Systematic Parallel & 19.9 & $2.2 \mathrm{e} 6$ & $1.3 \mathrm{e} 5$ \\
\hline Stratified Random & 10.0 & $1.1 \mathrm{e} 6$ & $8.7 \mathrm{e} 4$ \\
\hline Systematic Zigzag & 16.0 & $1.4 \mathrm{e} 6$ & $9.5 \mathrm{e} 4$ \\
\hline
\end{tabular}

TABLE 5. Model-based estimates of herring biomass, coefficient of variation, and weighted biomass.

\begin{tabular}{lccc}
\hline \hline Survey & $\begin{array}{c}\text { Biomass } \\
\text { (million mt) }\end{array}$ & $\begin{array}{c}\text { Coefficient } \\
\text { of variation }\end{array}$ & $\begin{array}{c}\text { Weighted Biomass } \\
\text { (million mt) }\end{array}$ \\
\hline Systematic Parallel & $\mathbf{2 0 0 0}$ & & \\
Stratified Random & 1.503 & 11 & \\
Systematic Zigzag & 1.584 & 17 & 1.427 \\
-------------------- & \\
& 1.268 & 10 & 1.819 \\
Systematic Parallel & 2001 & & \\
Stratified Random & 2.148 & 10 & \\
Systematic Zigzag & 1.596 & 15 & \\
\hline
\end{tabular}

but one that is unattainable. This is because the amount of time required to survey an area at $100 \%$ would be much greater than the time that the target species remains stationary. Choices of data analysis methods are dependent on the survey design and the goals of the fisheries managers. Certain analyses are more amenable to some data than others, and managers often have specific requirements for their assessments. Geostatistical, or model-based, methods take account of autocorrelation, whereas conventional, or design-based, statistics rely on uncorrelated data. Acoustic data are inherently autocorrelated, and should be more amenable to model-based analytical methods (Rivoirard et al., 2000; ICES, MS 2005). Absolute estimates or relative indices are important considerations, and measures of the variability in population trends may also be important. Although the results from the current analysis are only based on 2 replicates, practically speaking, it would be difficult to complete additional surveys. The results however, are consistent with simulation studies that looked at many replicates (ICES, MS 2005).
Herring on Georges Bank were distributed along a continuum from the Great South Channel to the northern edge of Georges Bank, a distance of roughly 300 km. Herring in this area were abundant on their historic spawning grounds along the 50-150 m isobaths. The three designs were equally suited for surveying and determining the extent of the distribution of herring both during 2000 and 2001. If one compares the statistical properties (CVs for example) from these acoustic surveys to other conventional survey methods such as bottom trawl results, all the acoustic surveys gave sensible and useful results that could be used in a stock assessment. If the objective was solely to produce an estimate of biomass, any of the three survey designs could be used.

If reducing statistical variability is a goal, then maximizing coverage is imperative. The zigzag design produced the lowest average geostatistical variance estimate for the two years. This is because the zigzag pattern maximizes transect distance relative to the amount of 

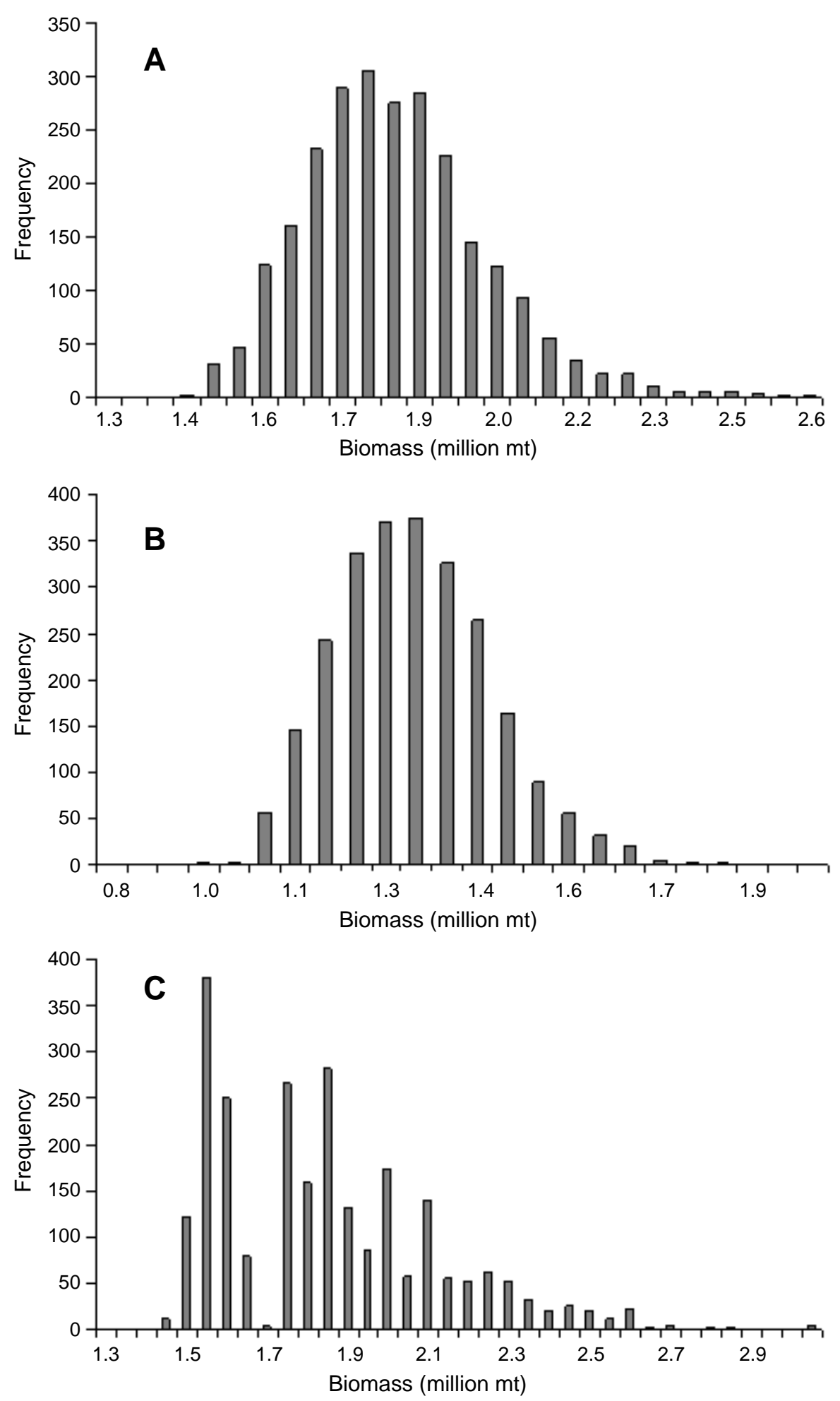

Fig. 7. Density plots for 2500 bootstrap estimates of biomass from herring in 2000: (A) parallel, (B) zigzag, and (C) stratified random survey. 

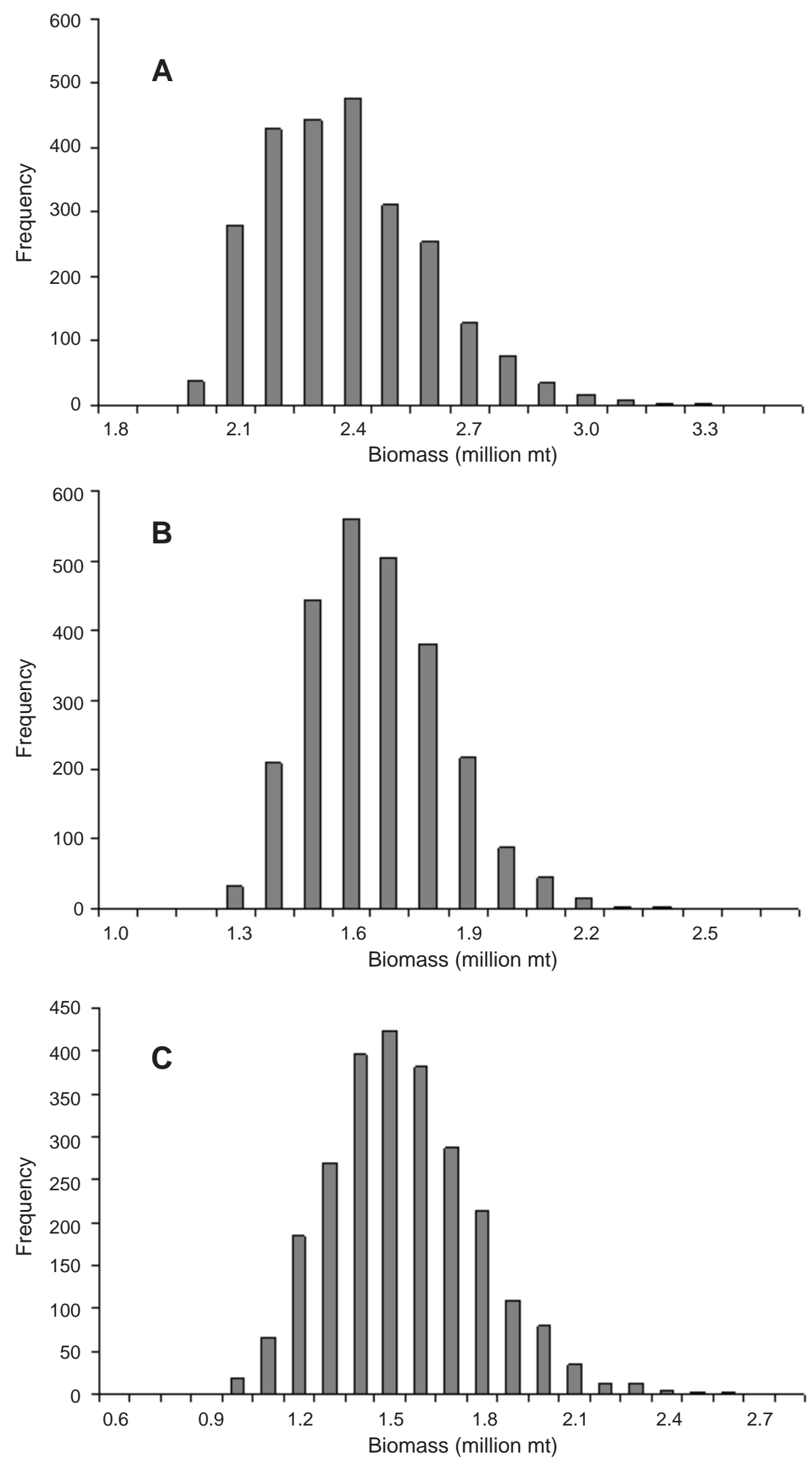

Fig. 8. Density plots for 2500 bootstrap estimates of biomass from herring in 2001: (A) parallel, (B) zigzag, and (C) stratified random surveys. 
TABLE 6. Median and $80 \%$ confidence intervals (10\%-90\%) of bootstrap estimates for herring biomass (designed based).

\begin{tabular}{|c|c|c|c|}
\hline \multirow[b]{2}{*}{ Survey } & \multicolumn{3}{|c|}{ Herring biomass (million $\mathrm{mt}$ ) } \\
\hline & Median & $10 \%$ & $90 \%$ \\
\hline \multicolumn{4}{|c|}{2000} \\
\hline Systematic Parallel & 1.761 & 1.567 & 2.003 \\
\hline Stratified Random & 1.747 & 1.470 & 2.168 \\
\hline Systematic Zigzag & 1.261 & 1.108 & 1.434 \\
\hline \multicolumn{4}{|c|}{2001} \\
\hline Systematic Parallel & 2.338 & 2.109 & 2.643 \\
\hline Stratified Random & 1.475 & 1.193 & 1.803 \\
\hline Systematic Zigzag & 1.601 & 1.404 & 1.846 \\
\hline
\end{tabular}

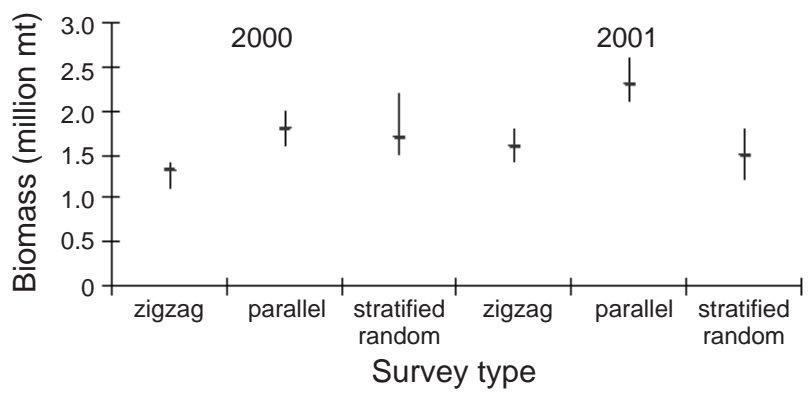

Fig. 9. Estimates of biomass (median and $80 \%$ CI) from 2500 bootstrap runs for herring surveys utilizing three designs in 2000 and 2001.

time surveying (Simmonds et al., 1992). Disadvantages to zigzag patterns are that the transect nodes are highly correlated, and extending transects during the survey to sample the unexpected occurrence of the species of interest is difficult to do without modifying the entire design. A stratified-random design is advantageous because effort can be allocated in proportion to the spatial distribution of the resource. However, a stratified-random survey design does not appear to be as amenable to model-based analysis, as the variability was consistently greater than the other designs in this and other studies (Simmonds et al., 1992; ICES, MS 2005). The increased variance is most likely due to less than optimal positioning of the transects relative to the spatial distribution of herring, and thus the design did not maximize spatial autocorrelation. As a consequence, less signal exists in the intra-distance measures used to fit the variograms and ultimately less precision is obtained in the geostatistical estimates. The estimates of the range for the stratified random surveys are both smaller than the range for the systematic surveys, indicating less spatial information is probably available from this design. Nonetheless, results from this survey design were still in close agreement with the other survey designs. Bootstrap results suggest that as long as a reasonable number of transects are allocated to each sampling stratum, reliable estimates of the mean and its precision can be obtained.

Logistically, the systematic parallel survey would be preferred, as the average variance from this design during 2000 and 2001 was only slightly greater than for the zigzag design and the lowest $\mathrm{CV}$ was obtained from this approach in 2001. This is consistent with theoretical and simulation results that suggest a parallel design will generally produce the most precise estimate of the mean for survey data with a reasonable level of spatial content (Rivoirard et al., 2000; Petitgas 2001; ICES, MS 2005).

A consistent and strong spatial autocorrelation pattern existed in the herring biomass data in this study. Analyses suggested that a persistent east-west spatial distribution pattern was present in the data across all surveys and during both years, indicating that the corrections that were applied were useful. Likewise, limiting the analysis to a relative distance of $50 \mathrm{nmi}$, based on an examination of several alternatives, helped to stabilize results. Variograms from these surveys suggest that a spherical model was useful for describing the spatial signal in the data, although a formal comparison with other spatial models was not completed.

Bootstrap analyses produced distributions of herring biomass that were fairly tight and symmetric. The exception was the stratified random design in 2000, but this was corrected by increasing sample size in 2001. The method of scaling design-based results with the geostatistical variance allowed estimates of precision to be calculated for the two systematic surveys. The mean biomass from 
this approach and 80\% CIs around the estimates were relatively precise for all the surveys.

\section{Summary}

Since time and sampling intensity are not limiting issues for herring surveys on Georges Bank, a systematic parallel design was selected as the optimal survey design for pre-spawning Atlantic herring, based on theory and the results from these surveys and comparisons. A modelbased analysis was chosen to provide biomass estimates and estimates of precision.

\section{Acknowledgements}

The authors would like to express thanks to the officers and crew of the NOAA FRV Delaware II and to the Northeast Fisheries Science Center for support of this work. Special thanks to Dr. Mike Fogarty for his help in reviewing the methods used in this analysis.

\section{References}

ANTHONY, V. C., and G. WARING. 1980. The assessment and management of the Georges Bank herring fishery. ICES Rapp. Proc.-Verb., 177: 72-111.

BAILEY, R. S., and E. J. SIMMONDS. 1990. The use of acoustic surveys in the assessment of the North Sea herring stock and a comparison with other methods. ICES Rapp. Proc.Verb., 189: 9-17.

BENIGNI, D., D. SHIELDS, S. CHANG, and N. McHUGH. 2004. Fisheries scientific computer system (FSCS) manual version 1.6. NOAA. Office of Marine and Aviation Operations and National Marine Fisheries Service, September, 2004. 75 p.

CRESSIE, N, and D. M. HAWKINS. 1980. Robust estimation of the variogram: 1. Math. Geo., 12: 115-125.

DEGNBOL, P., H. LASSEN, and K. J. STAEHR. 1985. In-situ determinations of target strength of herring and sprat at 38 and $120 \mathrm{kHz}$. Dana., 5: 45-54.

FOGARTY, M. J., and S. H. CLARK. 1983. Status of Atlantic herring resources in the Gulf of Maine region - 1983. NEFSC Ref. Doc., 83-46.

FOOTE, K. G. 1987. Fish target strengths for use in echo integrator surveys. J. Ac. Soc. Am., 82: 981-987.

1991. Summary of methods for determining fish target strength at ultrasonic frequencies. ICES J. Mar. Sci., 48: 211-217.

FOOTE, K. G., A. AGLEN, and O. NAKKEN. 1986. Measurements of fish target strength with a split-beam echosounder. J. Ac. Soc. Am., 80: 612-621.

FOOTE, K. G., H. P. KNUDSEN, G. VESTNES, D. N. MACLENNAN, and E. J. SIMMONDS. 1987. Calibration of acoustic instruments for fish density estimation: A practical guide. ICES Coop. Res. Rep., No.44.

GOOVAERTS, P. 1997. Geostatistics for natural resource evaluation. Oxford University Press, New York.

HAGSTROM, O., and I. ROTTINGEN. 1982. Measurements of the density coefficient and average target strength of herring using purse seine. ICES C.M. 1982/B:22: 13 p.

HALLDORSSON, O, and P. REYNISSON. 1983. On the behavior of the Icelandic summer spawning herring (C. harengus L.) during echo surveying and depth dependence of acoustic target strength in situ. ICES C.M. 1983/H:36: 35 p.

JECH, J. M., W. MICHAELS, W. OVERHOLTZ, W. GABRIEL, T. AZAROVITZ, D. MA, K. DWYER, and R. YETTER. 2000. Fisheries acoustic surveys in the Gulf of Maine and on Georges Bank at the Northeast Fisheries Science Center. In: Proceedings of the Sixth International Conference on Remote Sensing for Marine and Coastal Environments. 1-3 May, Charleston, South Carolina, USA. Veridian ERIM International, Ann Arbor, Michigan, USA. p. 168-175.

JOLLY, G. M., and I. HAMPTON. 1990. A stratified random transect design for acoustic surveys of fish stocks. Can. J. Fish. Aquat. Sci., 47: 1282-1291.

KALUZNY, S. P., S. C. VEGA, T. P. CARDOSO, and A. A. SHELLY. 1997. Splus spatial stats: users manual for windows and unix. Springer-Verlag, New York.

LASSEN, H., and K. J. STAEHR. 1985. Target strength of Baltic herring and sprat measured in situ. ICES C.M. 1985/B41: 14 p.

ICES. 2001. Study group on target strength estimation in the Baltic Sea. Seattle, WA, USA. 22-23 April 2001. ICES C.M. 2002/B:02: 16p.

2005. Report of the workshop on survey design and data analysis (WKSAD). Sette, France, 9-13 April 2005. ICES C.M. 2005/B:07: 166 p.

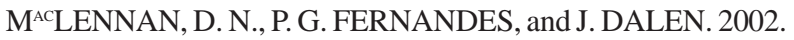
A consistent approach to definitions and symbols in fisheries acoustics. ICES J. Mar. Sci., 59: 365-369.

MARAVELIAS, C. D., D. G. REID, E. J. SIMMONDS, and H. HARALABOUS. 1996. Spatial analysis and mapping of acoustic survey data in the presence of high variability: geostatistical application to North Sea herring (Clupea harengus). Can. J. Fish. Aquat. Sci., 53: 1497-1505.

MICHAELS, W. L., and P. YUND. 2001. Report on the third northwest Atlantic herring acoustic workshop. NOAA Tech. Mem. NMFS-NE-166.

MISUND, O. A., and A. K. BELSTAD. 1995. Target strength estimates of schooling herring and mackerel by the comparison method. ICES Int. Sym. Fish. Plank. Ac., Aberdeen, UK 12-16 June, 1995. p. 281-284.

OVERHOLTZ, W. J., and K. D. FRIEDLAND. 2002. Recovery of the Gulf of Maine-Georges Bank Atlantic herring (Clupea harengus) complex: perspectives based on bottom trawl survey data. Fish. Bull., 100: 593-608.

OVERHOLTZ, W. J., L. D. JACOBSON, G. D. MELVIN, M. CIERI, M. POWER, D. LIBBY, and K. CLARK. 2004. Stock assessment of the Gulf of Maine-Georges Bank Atlantic Herring Complex, 2003. NEFSC Ref. Doc., No. 04-06, 290 p.

OVERHOLTZ, W. J., J. S. LINK, and L. D. JACOBSON. In prep. Developing an ecosystem approach for assessment advice and biological reference points for the Gulf of Maine-Georges Bank herring complex: adding predation mortality. N. Am. J. Fish. Mgt. (Submitted 2006). 
PETITGAS, P. 1993. Geostatistics for fish stock assessments: a review and an acoustic application. ICES J. Mar. Sci., 50: 285-298.

2001. Geostatistics in fisheries survey design and stock assessment: models, variance, and applications. Fish Fish., 2: 211-249.

REYNISSON, P. 1993. In situ target strength measurements of Icelandic summer spawning herring in the period 1985-1992. ICES C.M. 1993/B:40: 15 p.

RIVOIRARD, J., J. SIMMONDS, K. G. FOOTE, P. FERNANDES, and N. BEZ. 2000. Geostatistics for estimating fish abundance. Blackwell Science Ltd, Oxford, England.

RUDSTAM, L. G., T. LINDEM, and S. HANSSON. 1988. Density and in situ strength of herring and sprat: a comparison between two methods of analyzing single-beam sonar data. Fish. Res., 6: 305-316.

SIMMONDS, E. J. 2002. Weighting of acoustic and trawl survey indices for the assessment of North Sea herring. ICES J. Mar. Sci., 60: 463-471.
SIMMONDS, E. J., N. J. WILLIAMSON, F. GERLOTTO, and A. AGLEN. 1992. Hydroacoustic survey design and analysis procedure: a comprehensive review of current practice. ICES Coop. Res. Rep., No. 187: 112 p.

SMITH, W. G., and W. W. MORSE. 1993. Larval distribution patterns: early signals for the collapse/recovery of Atlantic herring Clupea harengus in the Georges Bank area. Fish. Bull., 91: 338-347.

SNEDECOR, G. W., and W. G. COCHRAN. 1972. Statistical Methods. The Iowa State University Press, Ames Iowa, USA.

TUPPER, M. H., V. C. ANTHONY, S. B. CHENOWETH, and H.

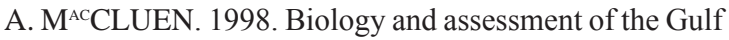
of Maine herring stocks. Gulf of Maine Research Institute, Portland, ME, 04112. 104 p.

VABO, R. 1999. Measurements and correction models of behaviorally induced biases in acoustic estimates of wintering herring (Clupea harengus L.). $\mathrm{PhD}$ Thesis, Bergen University, Bergen Norway, 158 p. 